\title{
SPECIAL COMMUNICATION \\ THE ROLE OF GENETICS IN THE UNDERSTANDING OF COMPLEX CONGENITAL HEART DISEASES
}

\author{
Sana Ashiq ${ }^{1}$, Muhammad Farooq Sabar ${ }^{1}$ \\ ${ }^{1}$ University of the Punjab, Lahore, Pakistan
}

One of the most dynamic organs in the human body is the heart. Cardiac development is regulated by two key factors including signaling and transcriptional pathways. Thus, during the development of the fetus, any factor that disrupts the normal functioning of these factors may lead toward congenital heart defects (CHDs). Congenital heart disease is a complex multifactorial disease that involves both environmental and genetic factors. ${ }^{1,2}$ It is defined as any defect that occurs during heart development either in the cardiac structure or its associated vessels. ${ }^{3}$ Globally, it is one of the most common reasons for infant mortality and one of the most common birth defects in paediatric patients. As a rough estimate, 8 infants in every thousand live births are born with this fatal disease. ${ }^{4}$

Every year, in Pakistan approximately 40,000 children suffered from CHDs. ${ }^{5}$ Clinically depending upon the disease severity congenital heart diseases can be divided into two major subgroups one is nonsyndromic and the other is syndromic. And among all these defects cardiac septation defects are the most common accounting for approximately $50 \%$ of the cases. ${ }^{6}$ It can be further sub-grouped as isolated lesions or complex diseases in combination with other heart defects. $^{3} \quad$ The exact mechanism involved in the pathogenesis of the congenital heart remains poorly understood but the most probable mechanism is multifactorial. Recent investigations suggest the role of epigenetic factors, micro RNA and small noncoding RNAs in the development of congenital heart defects. Moreover, advancements in molecular techniques including next-generation sequencing (NGS) helps in further detecting the genetic causes of CHDs such as the novel single nucleotide polymorphisms (SNPs) and copy number variants (CNVs). ${ }^{7}$

The current approaches used for genetic diagnosis of paediatric patients suffering from CHDs include karyotype analysis, copy number variation analysis, next-generation sequencing, and whole-genome or whole-exome sequencing. The targeted NGS relies on the selected region of know gene of interest and compared to whole genome or exome sequencing it provides us deeper gene coverage with easy variant detection at a lower cost. It provides robust detection of deletions, insertion and single nucleotide polymorphisms which chromosomal microarray analysis (CMA) and karyotyping cannot detect. To date, many pathogenic variants in different genes such as CITED2, CHD7, ZFPM2, MYH6 and KMT2D have been investigated by using targeted NGS. While whole-exome or genome sequencing help in the discovery of genes involves in the pathogenesis of congenital heart defects as it gives us more resolution at a single base-pair level.

Thus accurate genetic diagnosis can be done by using the appropriate diagnostic techniques that can ultimately help in better patient counseling and clinical outcome. ${ }^{8}$ Furthermore, personalized medicines or finding mutations responsible for individual congenital heart disease patients can direct to better outcomes and approaches for each cardiac malformation phenotype. Thus, ultimately combined data of patients genotypic and phenotypic following well-designed guidelines will accelerate the translation of each SNP information into better treatment and clinical insights. ${ }^{9}$

Keywords: NGS, Single nucleotide polymorphisms, CHDs.

\section{REFERENCES}

1. Ashiq S, Ashiq K. Genetic perspective of the congenital heart disease. Pak Heart J. 2020;53(3):1-3.

2. Wang H, Liu Y, Li Y, Wang W, Li L, Meng M, et al. Analysis of NKX2-5 in 439 Chinese patients with sporadic atrial septal defect. Medical Sci Monit. 2019;25:2756.

3. Ashiq S, Ashiq K, Sabar MF. The role of NKX2-5 gene polymorphisms in congenital heart disease (CHD): a systematic review and meta-analysis. Egypt Heart J. 2021;73(1):1-9.

4. Zhao M, Diao J, Huang P, Li J, Li Y, Yang Y, et al. Association of maternal diabetes mellitus and polymorphisms of the NKX2. 5 gene in children with congenital heart disease: a single centre-based case-control study. J Diabetes Res. 2020;2020:3854630.

5. Hussain S, Sabir MU, Afzal M, Asghar I. Incidence of congenital heart disease among neonates in a neonatal unit of a tertiary care hospital. J Pak Med Assoc. 2014;64(2):175-8.

6. Wolf M, Basson CT. The molecular genetics of congenital heart disease: a review of recent developments. Curr Opin Cardiol. 2010;25(3):192.

7. Muntean I, Togănel R, Benedek T. Genetics of congenital heart disease: past and present. Biochem Genet. 2017;55(2):105-23. 
8. Qiao F, Hu P, Xu Z. Application of next-generation sequencing for the diagnosis of fetuses with congenital heart defects. Curr Opin Obstet Gynecol. 2019;31(2):1328.

9. Pasipoularides A. The new era of whole-exome sequencing in congenital heart disease: brand-new insights into rare pathogenic variants. J Thorac Dis. 2018;10(Suppl 17):S1923-29.

\section{Address for Correspondence:}

Dr. Sana Ashiq, Centre for Applied Molecular Biology, University of the Punjab, 87-West Canal Bank Road, Thokar Niaz Baig, Lahore 53700, Pakistan

Email:sanaashiq72@gmail.com

Citation: Ashiq S, Sabar MF. The Role of Genetics in the Understanding of Complex Congenital Heart Diseases. Pak Heart J. 2021;54(04):383-384. https://doi.org/10.47144/phj.v54i4.2210 